This item was submitted to Loughborough's Research Repository by the author.

Items in Figshare are protected by copyright, with all rights reserved, unless otherwise indicated.

\title{
Analysis of anisotropic viscoelastoplastic properties of cortical bone tissues
}

PLEASE CITE THE PUBLISHED VERSION

http://dx.doi.org/10.1016/j.jmbbm.2010.10.001

\section{PUBLISHER}

(c) Elsevier

VERSION

AM (Accepted Manuscript)

LICENCE

CC BY-NC-ND 4.0

\section{REPOSITORY RECORD}

Abdel-Wahab, Adel A., Khurshid Alam, and Vadim V. Silberschmidt. 2019. "Analysis of Anisotropic Viscoelastoplastic Properties of Cortical Bone Tissues”. figshare. https://hdl.handle.net/2134/8380. 
This item was submitted to Loughborough's Institutional Repository (https://dspace.lboro.ac.uk/) by the author and is made available under the following Creative Commons Licence conditions.

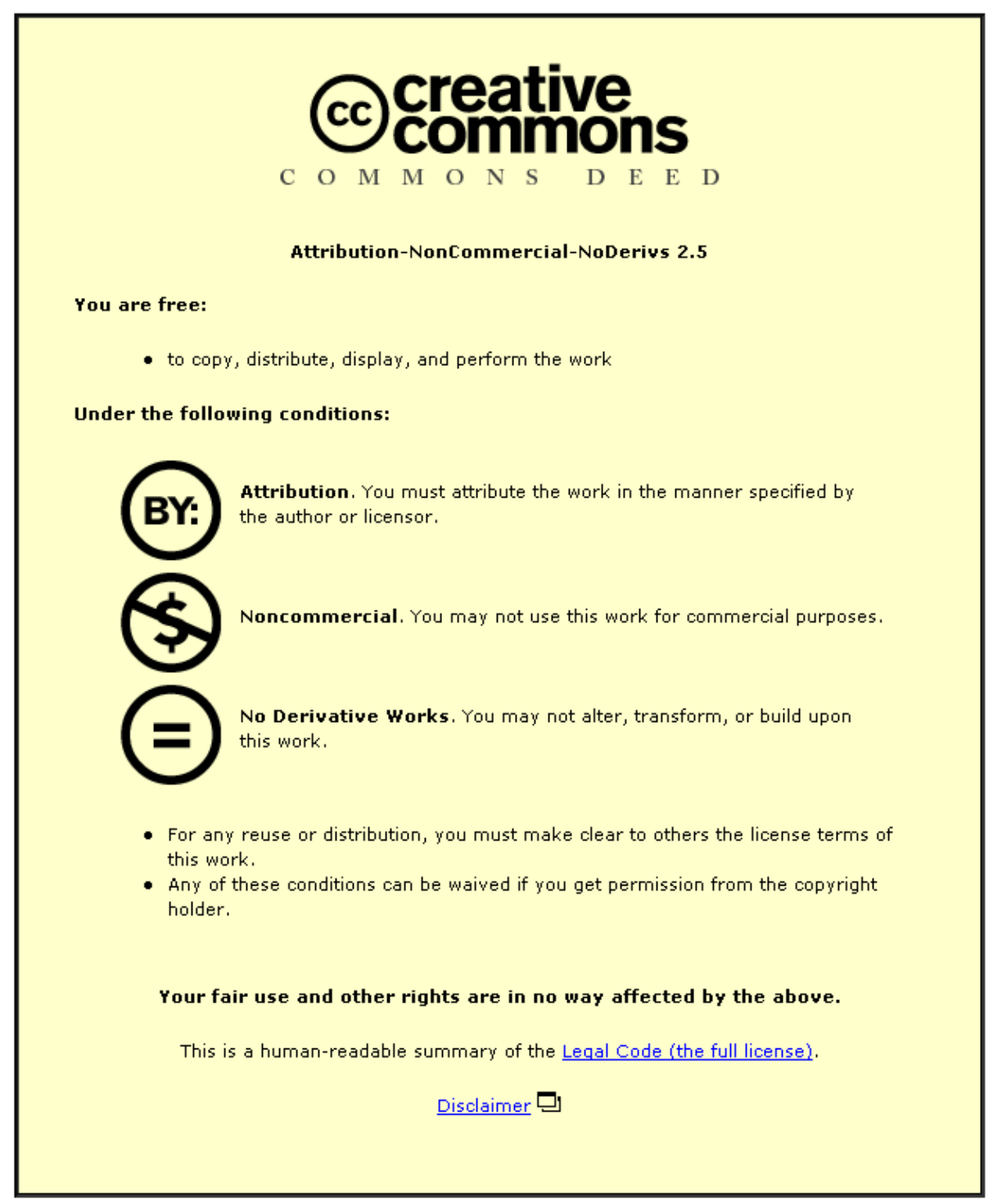

For the full text of this licence, please go to: http://creativecommons.org/licenses/by-nc-nd/2.5/ 


\title{
Analysis of Anisotropic Viscoelastoplastic Properties of Cortical Bone Tissues
}

\section{Adel A. Abdel-Wahab, K. Alam and Vadim V. Silberschmidt}

Wolfson School of Mechanical and Manufacturing Engineering, Loughborough

$$
\text { University, UK }
$$

\begin{abstract}
Bone fractures affect the health of many people and have a significant social and economic effect. Often, bones fracture due to impacts, sudden falls or trauma. In order to numerically model the fracture of a cortical bone tissue caused by an impact it is important to know parameters characterising its viscoelastoplastic behaviour. These parameters should be measured for various orientations in a bone tissue to assess bone's anisotropy linked to its microstructure. So, the first part of this study was focused on quantification of elastic-plastic behaviour of cortical bone using specimens cut along different directions with regard to the bone axis - longitudinal (axial) and transverse. Due to pronounced non-linearity of the elastic-plastic behaviour of the tissue, cyclic loadingunloading uniaxial tension tests were performed to obtain the magnitudes of elastic moduli not only from the initial loading part of the cycle but also from its unloading part. Additional tests were performed with different deformation rates to study the bone's strain-rate sensitivity. The second part of this study covered creep and relaxation properties of cortical bone for two directions and four different anatomical positions anterior, posterior, medial and lateral - to study variability of bone's properties. Since viscoelastoplasticity of cortical bone affects its damping properties due to energy dissipation, the Dynamic Mechanical Analysis (DMA) technique was used in the last part of our study to obtain magnitudes of storage and loss moduli for various frequencies.
\end{abstract}


Based on analysis of elastic-plastic behaviour of the bovine cortical bone tissue, it was found that magnitudes of the longitudinal Young's modulusfor four cortical positions were in the range of 15-24 GPa, while the transversal modulus is lower - between 10-15 GPa. Axial strength for various anatomical positions was also higher than transversal one with a significant differences in magnitudes for those positions.. Quantitative data obtained in creep and relaxation tests exhibited no significant position-specicifc differences.. DMA results demonstrated relatively low energy loss capability due to viscosity of bovine cortical bone that has a loss factor in the range of 0.035-0.1.

\section{Introduction}

Two of the principal functions of the human skeleton system are to bear the necessary mechanical forces and to protect vital organs in the body. To achieve those functions, the skeleton system should have adequate mechanical properties such as strength, stiffness, and fracture toughness (Yamashita et al., 2001). Due to age-based properties deterioration together with an increased fracture susceptibility as an outcome of structural changes, various experimental studies investigating the effect of structural properties of the cortical bone and its mechanical properties have been conducted (Zioupos and Curry, 1998; Zioupos et al., 1999; Wachter et al., 2002; Curry, 2004; Augat and Schorlemmer, 2006). They have been devoted to acquisition of the respective data at different hierarchical levels - macrosopic and microscopic - and using different methodological approaches. Since bone is a viscoelastic material, sensitive to a strain rate level, one of the most important factors that should be considered in testing its properties is the effect of the deformation rate. For instance, uniaxial tensile tests were performed on longitudinal adult bovine femora cortical bone over a wide range of strain rates - from 
$5.3 \times 10^{-4}$ to $237 \mathrm{~s}^{-1}$ (Wrightt et al., 1976). In another study, the mechanical properties of bovine cortical bone tissue were investigated at high strain-rates using a split Hopkinson Pressure Bar (SHPB) method (Ferreria and Simoes, 2005). In that study, in both longitudinal and transverse directions linear dependences of both the elastic modulus and ultimate strength upon the strain rate were found; the ultimate strength was higher and elastic moduli were lower for higher strain rates. The difference between quasi-static properties from the literature and the dynamic properties obtained in that study was attributed to different bone failure mechanisms. An attempt to assess mechanical properties of human femoral cortical bone at an intermediate strain rate of $4 \times 10^{-2} \mathrm{~s}^{-1}$ was presented in (Raftopoulos et al., 1993). The dynamic loading was applied by dropping weights from different heights over specimens cut along the direction of a femur axis. The Young's modulus obtained at that intermediate strain was $10.5 \%$ higher than that for the low strain rate of $2 \times 10^{-5} \mathrm{~s}^{-1}$ and $10 \%$ lower than that for the higher strain rate of $10^{2} \mathrm{~s}^{-}$ ${ }^{1}$. The Poisson's ratio did not show any significant difference for the three strain rate levels. Another approach - an ultrasonic method - was used to characterise bone's orthotropy and measure the appropriate number of elastic constants needed to describe the elastic properties of the cortical bone tissue (Yoon et al., 1976; Bonfield and Tully, 1982; Rho, 1996; Lasaygues et al., 2001; Phithioux et al., 2002). Evaluating only the anisotropic elastic properties of cortical bone tissue utilizing quasi-static and/or ultrasonic method is still in the centre of analysis. Assessment of dynamic and time-dependent mechanical properties becoming more important, especially for dealing with dynamic loading events. The viscoelastic properties of the cortical bone help in understanding such issues as its damping characteristics and the level of dissipated energy in the fracture 
process. Only a few studies deal with viscoelastic properties of cortical bone. Some studies were conducted to investigate its creep and relaxation behaviour. For instance, multiple-cycle tensile creep tests were carried out for human and bovine cortical bone tissues in (Fondrk et al., 1988). The results of that study suggested an existence of a stress threshold, above which time-dependent effects dominate the material response and below which the behaviour is primarily linear viscoelastic, with time effects playing only a secondary role. In another study (Cotton et al., 2005), it was concluded that the evolution of damage measured as an incremental drop in the modulus per cycle - for specimens from a femoral cortex tested in zero tension fatigue until failure - was associated with the stress level and with the creep rate. Moreover, different studies showed that cortical bone tissues exhibit a creep behaviour (Smith and Walmsley, 1957; Sedlin, 1965; Uteri'kin and Sveshnikova, 1973; Vilks and Kent, 1975). It was demonstrated in different studies that relaxation properties of the cortical bone tissue change with water content (Curry 1965; Lakes et al., 1979a, Sasaki and Atsushi, 1995).. Dynamic mechanical analysis (DMA) was also used to study tissue's properties. The effect of mineral content on dynamic mechanical thermal behaviour was investigated for fresh bovine femur specimens with the use of dynamic mechanical thermal analysis (DMTA) together with the effect of reducing bone mineral content (BMC) on microstructure of the collagen fibres and denaturation temperatures (Wang and Freng, 2005). Temperature was scanned from $20^{\circ} \mathrm{C}$ to $300^{\circ} \mathrm{C}$ at the scanning rate of $2^{\circ} \mathrm{C} / \mathrm{min}$ and a loading frequency of $1 \mathrm{~Hz}$. Also, measurements were conducted on entire bone specimens in order to evaluate viscoelastic properties of bone for all hierarchical levels. In that study, the effect of an inorganic phase was analysed by measuring demineralised 
bone as well as collagen specimens. Fresh ulna specimens were tested using dynamic mechanical analysis in the temperature range from $-50^{\circ} \mathrm{C}$ to $80^{\circ} \mathrm{C}$, at a constant frequency of $1 \mathrm{~Hz}$ (Mano, 2005). Based on the evidence that damage, viscoelastic, stiffness and post-yield mechanical properties are related in bone tissue, the influence of the presence of a flaw on apparent viscoelastic properties of cortical bone tissue was studied in (Yeni et al., 2004) as well as the effect of flaw orientation on apparent viscoelasticity utlizing DMA as a non-destructive means for damage detection. It was demonstrated that a cortical bone tissue exhibited different viscoelastic behaviour in the presence of a flaw and depended on the flaw's orientation. Therefore, based on those results in-vivo techniques were proposed for damage detection.

In order to model and simulate a cortical bone subjected to loading types that may be experienced in vivo; especially those involving impact events, a constitutive models that capture elastic, plastic and time-dependent behaviours are required. Therefore, a quasistatic, viscoelastic and viscoplastic properties of the cortical bone tissue are needed to calibrate those models' parameters. A recent study proposed a viscoelastic, viscoplastic model of cortical bone valid at low and high strain-rates (Johnson 2010); it can be implemented in a finite-element model to simulate impact events. An orthotropic elastic assumption together with a plasticity model such as Johnson-Cook plasticity model can also be used in simulations incorporate other characteristic types of deformational behaviour .

The hierarchically organized multi-level structure of bones with optimized arrangement its constituents and their different orientations makes bone heterogeneous and anisotropic material (Rho 1998). Therefore, tests of mechanical properties should be performed for 
specimens from different positions and for different orientations with regard to bone's axes. . Accordingly, this study was devoted to analysis of such properties for two different directions - axial and transversal - as well as for different anatomical positions known as anterior, posterior, medial, and lateral. The bovine femur was chosen as a material for experimental study due its dimensions allowing extraction of a significant number of specimens with reasonable dimensions as well as closeness of its properties to those of human femur Currently, most of the available data in the literature are only given for the longitudinal direction, with no information about the anatomical position from which the specimens were excised. Hence, a more comprehensive analysis of these effects is needed. This study of a deformational behaviour of a bovine femoral cortical bone tissue for directions along the bone axis and perpendicular to it for different anatomical positions is divided into three main parts:

(i) Investigation of quasi-static mechanical properties together with the strain-rate sensitivity to obtain parameters of an elastic-plastic constitutive model for finite-element simulations;

(ii) Analysis of creep and relaxation properties to obtain viscoelastic constitutive model parameters and verify finite-element simulations;

(iii) A DMA study of viscous properties in a frequency range $0.1 \mathrm{~Hz}-100 \mathrm{~Hz}$ to assess their variability and for further implementation into transient finiteelement models .

\section{Materials and Methods}

\subsection{Preparation of specimens}

Comment [VS1]: Include a respective reference here 
Specimens - for all of our studies - were cut from fresh bovine femur bones (aged 1.5-2 years). The mid-part of five femora (diaphysis) were extracted using a handsaw. Specimens were cut from four anatomical positions parallel and transverse to the bone axis using a milling machine, equiped with an irrigation system. After cutting the specimens they were divided into four groups - A, B, C and D. Group A was allocated for a study of quasi-static mechanical properties, group B for strain-rate sensitivity measurements, group $\mathrm{C}$ for a creep/relaxation analysis, and group D for DMA tests. Specimens for those groups were excised with orientations shown in Fig. 1 and with dimensions given in Table 1. After cutting the specimens with a milling machine, they were ground under tape water, using a series of grinding papers Standard ANSI grit 240,600 and 1200 , to improve the surface quality and to avoid any scratches that might affect the results. Then specimens were stored frozen at $-20^{\circ} \mathrm{C}$ in $0.9 \%$ saline solution until tested. Figure 2 shows the specimen's preparation process and the final shape of the specimens in group A.

\section{$2.2 \quad$ Experimental procedures}

All the tests, apart from DMA, were performed using an Instron MicroTester 5848 machine that allowed testing relatively small specimens (Fig. 3a). An extensometer with a gage length of $10 \mathrm{~mm}$ was used to measure displacements. It was noticed that the cortical bone specimens dry quickly after taken from the refrigerator so water was sprayed in regular intervals over the specimen's surface during the test to keep it wet. The experiments were performed at room temperature $\left(20^{\circ} \mathrm{C}\right)$.

\subsubsection{Elastic-plastic behaviour}


This part of the study was focused on quantification of elastic-plastic behaviour under cyclic uniaxial tension, in the axial direction of long bones, parallel to the osteons, as well as in the transverse direction perpendicular to them. Two cycles of displacement-control loading with increasing amplitude were applied to each specimen during a uniaxial tension test. Due to different load-carrying capacities of longitudinal and transverse specimens, the limits of loading cycles were different for those directions (see Table 2). Those limits were defined in monotonic tensile tests carried out until full fracture for specimens along and transverse to bone axis as well as from four anatomical positions. The specimens in that series of experiments were tested at a strain rate of $10^{-3} \mathrm{~s}^{-1}$. Three different types of parameters were determined in those tests: (i) Young's moduli, obtained using a tangent for the initial portion of the stress-strain curve as well as for the unloading parts of the cyclic tests; (ii) anisotropy ratios, calculated as the ratio of respective magnitudes for longitudinal and transverse directions and (iii) ultimate tensile strength.

\subsubsection{Strain-rate sensitivity}

Uniaxial monotonic tension tests were also conducted at different rates of displacement to investigate the effect of strain rate on the pre-yield and post-yield stress-strain behaviour. The displacement rate range used was between $10^{-4} \mathrm{~mm} / \mathrm{s}$ and $10 \mathrm{~mm} / \mathrm{s}$ corresponding to strain rates $10^{-5} \mathrm{~s}^{-1}$ and $1 \mathrm{~s}^{-1}$, respectively. Total of 20 specimens - along the femur bone's axis and from four different anatomical positions - were used for that experiment, and results were considered only for those specimens that were broken at the gage length; four specimens not meeting that condition were excluded from the analysis. 


\subsubsection{Creep and relaxation behaviour}

This part of the experimental study covered creep and relaxation properties of bovine femoral cortical bone. Various levels of stress in creep and strain in relaxation tests were employed. Three specimens for each direction and position were assigned for creep as well as three for relaxation test. The method file for Instron MicroTester was prepared with the stress ramping from zero to a defined stress level in 5 seconds and remaining afterwards constant for 3600 seconds. Such test can be helpful for finite-element verification when implementing data obtained from other tests, i.e., relaxation or DMA. The stress levels were chosen to be fractions of the $0.2 \%$ yield point that was obtained in the cyclic test (see Section 2.2.1). Three stress levels were applied, with values of 17 MPa, $19 \mathrm{MPa}$ and $21 \mathrm{MPa}$. To study another viscoelastic phenomenon for bovine femoral cortical bone - relaxation - extensions ramped from zero to specific levels within 5 seconds were applied. After that the extension remained constant for 1800 seconds; it was observed that the stress decreased with time. The used levels of initial extension were $0.15 \mathrm{~mm}, 0.2 \mathrm{~mm}$ and $0.255 \mathrm{~mm}$. One of relaxation specimens, extended by $0.2 \mathrm{~mm}$ was loaded for $3600 \mathrm{~s}$ to be used for obtaining coefficients of Prony series. The viscoelastic material model is defined as follows using that technique:

For a small strain tension test with a constant tension strain $\varepsilon$ applied to the material, the stress response $\sigma(t)$ can be defined by the viscoelastic material model:

$$
\sigma(t)=E_{R}(t) \varepsilon, \text { for } t>0
$$

where $E_{R}(t)$ is a relaxation modulus. The viscoelastic material has an asymptotic constant stress level for $t \rightarrow \infty$, in other words, $E_{R}(t) \rightarrow E_{\infty}$.

The relaxation modulus can be written in dimensionless form as: 


$$
e_{R}(t)=E_{R}(t) / E_{0},
$$

where $E_{0}=E_{R}(0)$ is the instantaneous modulus, so the expression of the stress takes the form:

$$
\sigma(t)=E_{0} e_{R}(t) \varepsilon
$$

The dimensionless relaxation function has the limits of $e_{R}(0)=1$ and $e_{R}(\infty)=E_{\infty} / E_{0}$. The viscoelastic material is defined by a Prony series expansion of the dimensionless relaxation modulus in the following way:

$$
e_{R}(t)=1-\sum_{i=1}^{N} e_{i}\left(1-e^{-t / \tau_{i}}\right)
$$

where $e_{i}, \tau_{i}, i=1,2, \ldots, N$, are material constants.

\subsubsection{Dynamic mechanical analysis}

To understand the damping behaviour of the cortical bone tissue due to its viscoelasticity, the dynamic mechanical analysis method was used. The advantage of this method is that it provides a wide range of data that cannot be obtained with other approaches. Another advantage is the use of small-size specimens. The DMA system used for those tests was STA861e manufactured by METTLER TOLEDO that has sufficient resolution and a working range: the frequency range is $0.001-1000 \mathrm{~Hz}$, while tan $\delta$ resolution is $10^{-5}$ and the modulus precision is $0.2 \%$. The force range is $0.005 \mathrm{~N}$ to $40 \mathrm{~N}$ and the force resolution is $0.15 \mathrm{mN}$, while the displacement range is $\pm 1.6 \mathrm{~mm}$ with resolution $0.6 \mathrm{~nm}$. A special temperature-resistant, linear variable differential transformer (LVDT) measures the displacement over th wide range with hogh accuracy. To measure deformation only of a sample, the LVDT is located as close as possible to it. This eliminates any other deformation effects (e.g. caused by a system's stand)improving accuracy of measurement of the delay time (i.e. phase shift) between the force and displacements.. In addition, to 
improve the reproducibility of displacement measurements, the temperature of the LVDT sensor is measured and any deviations from the reference temperature are compensated. For the tests, 24 identical specimens were excised from the bovine femoral cortical bone, three for every anatomical positions and direction. The specimens' dimensions are given in Table 1. A large clamping tension mode assembly of the system was used in those tests as shown in Fig. 3b. A displacement scan pilot study was conducted at the beginning to investigate a linear viscoelastic range of the cortical bone specimen and then to choose correctly the required force and displacement for the subsequent frequency scan tests. The maximum force amplitude of $9.1 \mathrm{~N}$ and the maximum displacement amplitude of $0.88 \mu \mathrm{m}$ were chosen to achieve linear viscoelasticity behaviour in the tests. For tensionmode frequency scan tests, the recommended manufacture frequency range is $0.1 \mathrm{~Hz}-$ $200 \mathrm{~Hz}$. But in our study, to make sure that the results were not affected by the resonance of the machine-specimen system, the upper limit of the frequency range was chosen at $100 \mathrm{~Hz}$. The specimens were tested in that range with a logarithmic increment of 10 steps/decade. The moduli are calculated from the measured specimen stiffness, the later can be influenced by a change in specimen's geometry. The geometry factor can be calculated by dividing the specimen length and its cross-sectional area. The average geometry factor for the specimen dimensions used was $788.931 / \mathrm{m}$. The storage modulus E' (equivalent to the Young's modulus), loss modulus E" and loss factor tan $\delta$ (an indication of the dissipated energy by the viscous mechanism relative to the stored energy) were measured for each specimen. Measurements were executed at ambient temperature of $20^{\circ} \mathrm{C}$. The offset force control was activated to prevent the buckling of the 
specimen so that accurate length measurements could be made. The auto-mode was chosen in the tests with a $150 \%$ offset force.

\section{Results}

\subsection{Elastic-plastic behaviour}

A non-linear elastic-plastic behaviour with strain hardening was observed for both longitudinal and transverse directions and all the four anatomical positions. Typical curves obtained at loading-unloading cycles at moderate strains are shown in Fig. 4. The Young's moduli as well as the ultimate strengths for bovine femoral cortical bone tissues in longitudinal and transverse directions for the four anatomical positions are provided in Table 3. Comparison of those values demonstrates small differences. The common feature of the differences is that values obtained for unloading cycles were higher than the initial ones and closer to each other. It demonstrates that non-elastic components are present at the very early stages of deformation, making the measurements based on unloading more adequate. It was found for tests along the bone axis that anterior specimens had the highest Young's moduli (see Table 1), and ultimate strength, while lateral ones were the weakest. The measured values of the Young's modulus for all anatomical positions were in the range of $15-24 \mathrm{GPa}$. One-way ANOVA statistical analysis revealed a significant difference among the four anatomical positions for both the Young's moduli and the ultimate strength. The initial, first-cycle and second-cycle magnitudes of the Young's modulus represent significant difference $(p=0.004, p=0.003$ and $\mathrm{p}=0.002$, respectively). The Scheffe's Post Hoc test was used to isolate group differences; they were found between lateral-anterior $(\mathrm{p}=0.005, \mathrm{p}=0.004$ and $\mathrm{p}=0.001)$, and medial-lateral $(\mathrm{p}=0.027, \mathrm{p}=0.013$ and $\mathrm{p}=0.003$ ) for initial, first and second Young's

Comment [VS2]: We don't need repeating the data available in the Table 3

Comment [VS5]: [Ref???] 
moduli, respectively. On the other hand, for specimens cut perpendicular to the bone axis, the medial ones had the highest Young's moduli. The average values of the Young's modulus measured perpendicular to the bone axis were in the range of $10-15 \mathrm{GPa}$ for all anatomical positions. A significant difference was also found for the specimens oriented along the transverse direction $(\mathrm{p}=0.002, \mathrm{p}=0.002$ and $\mathrm{p}=0.001)$ for initial, first- and second-cycle Young's modulus values. They were found between posterior-anterior $(\mathrm{p}=0.025, \mathrm{p}=0.02$ and $\mathrm{p}=0.002)$, posterior-medial $(\mathrm{p}=0.003, \mathrm{p}=0.004$ and $\mathrm{p}=0.001)$ and medial-lateral $(\mathrm{p}=0.018, \mathrm{p}=0.032$ and $\mathrm{p}=0.007)$ for those parameters, respectively.

In terms of ultimate strength, for longitudinal specimens the highest average level of 117.6 MPa was found for anterior specimens, whereas the lowest (65.5 MPa) was for lateral specimens. Statistical analysis confirmed existence of the significant differences among the groups: $\mathrm{p}=0.022$. For transversal specimens, medial ones revealed highest fracture stress of $39.0 \mathrm{MPa}$, while the lowest level of $25.4 \mathrm{MPa}$ was measured for anterior specimens. A significant difference $(\mathrm{p}=0.012)$ was found for results for transverse specimens from various anatomical positions. The value for three different pairs anterior-medial, posterior-medial and medial-lateral - are 0.025, 0.045 and 0.04, respectively. In general, the ultimate strength was higher for the longitudinal direction. The experimental data confirms anisotropy of cortical bone; the anisotropy ratios for initial, first- and second-cycle moduli are given in Table 4. Small differences among those ratios were found when comparing the three different moduli. The lateral anatomical position demonstrated the lowest anisotropy ratio, close to 1.4 , whereas the posterior anatomical position the highest, close to 2 . The medial specimens have the ratios close to those of lateral ones, while the anterior position is closer to the posterior in 
this respect. Statistical results showed significant difference $(\mathrm{p}=0.01)$ of anisotropy ratio between groups. The literature data give the range for anisotropy ratios between 1.5 and 2 (Ferreira et al., 2005; Raftopoulos et al., 1993). The fracture strain for the longitudinal direction in all anatomical positions was in the range from $0.4 \%$ to $1.1 \%$ and in the transverse direction was between $0.2 \%$ and $0.6 \%$. These values are smaller than that reported in (Reilly and Burstein, 1975; Burstein et al., 1976).

\subsection{Strain-rate sensitivity}

A sample test results for longitudinal posterior specimens showed elastic-plastic behaviour of initial linear response followed by (linear) hardening up to failure. Obviously, the strain rate had an effect on the elastic modulus, see Fig. 5. At the lowest strain rate $\left(10^{-5} \mathrm{~s}^{-1}\right)$, the value of the elastic modulus was $12 \mathrm{GPa}$, whereas at the strain rate of $10^{-3} \mathrm{~s}^{-1}$ and above the elastic modulus was $21 \mathrm{GPa}$. The fracture stress increased by some $60 \%$ for strain rates changing between $10^{-5} \mathrm{~s}^{-1}$ and $10^{-3} \mathrm{~s}^{-1}$. This difference drops to about $11 \%$ when the strain rate increases from $10^{-3} \mathrm{~s}^{-1}$ to $1 \mathrm{~s}^{-1}$. Due to the slippage between the specimen and the machine holding grips, higher strain rates were not studied.

\subsection{Creep and relaxation behaviour}

Results of creep tests are presented in Fig.6 that shows the evolution of strain for three identical bovine cortical femoral bone specimens subjected to three different levels of stress. It is observed that as the stress ramped from zero to the defined values in 5 seconds, the strain also ramped in an elastic manner. The values of the linear strains for anterior longitudinal bovine cortical bone tissues were $0.17 \%, 0.25 \%$, and $0.29 \%$ and the 
plastic strains were $0.021 \%, 0.025 \%$, and $0.033 \%$ for stress levels 17,19 , and $21 \mathrm{MPa}$, respectively.

The Norton's creep law for secondary creep at medium stress levels has the form:

$$
\varepsilon_{s}=A(T) \sigma^{n},
$$

where $\varepsilon_{s}$ is a secondary creep rate, $A(T)$ is a material parameter depending on temperature, $\sigma$ is applied stress and $n$ is a material constant. $A(T)$ and $n$ can be found from the intersect and the slope of the graph of a strain rate versus the constant applied stress curve in double logarithmic co-ordinates.

By applying the Norton's creep law to the experimental data obtained for the secondarycreep stage of the experiments characterised by the constant strain rate for both longitudinal and transverse directions, no significant difference $(\mathrm{p}=0.005)$ between respective values for the material constants was found. The average values of the constants were $n=2.7$ and $A=3.75 \times 10^{-11} \mathrm{MPa}^{-\mathrm{n}} \mathrm{s}^{-1}$. The tangent of the strain= time curve was calculated using MATLAB; its nearly constant magnitude was used to define the secondary creep stage.

Another viscoelastic phenomenon was investigated in this work - relaxation. Non-linear relations for stress relaxation with time for three different deformation levels of anterior longitudinal bovine femoral cortical bone are given in Fig. 7. The initial corresponding stresses were 21.2 $\mathrm{MPa}, 25.6 \mathrm{MPa}, 29.7 \mathrm{MPa}$ for initial deformations of $0.15 \mathrm{~mm}, 0.2$ $\mathrm{mm}$ and $0.255 \mathrm{~mm}$, respectively. In $1800 \mathrm{~s}$ those values decreased by $17.6 \%, 13.4 \%$ and $14.7 \%$, respectively. Again, no significant difference $(\mathrm{p}=0.02)$ was found between relaxation stresses for different directions or different anatomical positions of tested specimens. From the obtained experimental results on relaxation it was possible to 
determine the time-dependent constitutive equations for cortical bone based on the stress and strain history as well as the loading rate and time of load application to the specimen. A common form for those constitutive equations employs a Prony series that were calculated with the material evaluation technique provided by Abaqus finite-element software (Abaqus, Theory manual, 2001), as discussed in Section 2.2.3.

The calculated constants of the seriesare provided in Table 5 for a deformation level of $0.2 \mathrm{~mm}$ for a medial longitudinal cortical bone specimen for a time period of $3600 \mathrm{~s}$. Also, both experimental and calculated results for the dimensionless relaxation modulus are shown in Fig. 8. Apparently, even a series truncated to two terms provides a good approximation for experimental data.

\subsection{Dynamic mechanical analysis}

Three different parameters, describing viscoelasticity of the bovine cortical tissue, were measured in those experiments: storage modulus E', loss modulus E", and loss factor tan $\delta$. Curves of averaged values - together with respective data spread - for storage modulus E' for the longitudinal and transverse directions are shown in Figs. 9 and 10, respectively, for various anatomical positions. The storage modulus of the bovine femoral cortical bone tissue generally increases with the growing frequency for all the anatomical positions and directions, with some decrease in the frequency range of $50 \mathrm{~Hz}-100 \mathrm{~Hz}$. The increase in the storage moduli with the increase of the frequency is consistent with the strain-rate sensitivity results: as the strain-rate grows the elastic modulus increases. There were noticeable differences $(\mathrm{p}=0.01)$ in the values of the storage modulus for four anatomical positions in both longitudinal and transverse directions (see Table 6 for 
details). The storage moduli were compared at frequencies of $0.1 \mathrm{~Hz}$ and $10 \mathrm{~Hz}$. This is a physiological frequency range of the normal human activities from the slow walk to running in sports according to Sweeney et al. (1965). For the longitudinal direction at those frequencies, the highest storage modulus value was observed for lateral specimens, while the posterior ones had the lowest. For the transverse direction, specimens from the anterior part showed the highest values; the lowest ones were for posterior position, the same as for the longitudinal direction. The storage moduli for all positions for longitudinal and transverse directions were within the ranges 7 - 12 GPa and 5 - $7 \mathrm{GPa}$, respectively. The values of elastic moduli measured using DMA in this study were consistently lower (by a factor close to 2) than those obtained in quasi-static uniaxial tension tests. Tan $\delta$, used to characterise the dissipated energy due to viscous mechanism, was compared for the four anatomical positions for both longitudinal and transverse directions, (Fig. 11). The overall tendency for the loss factor is to decrease with the frequency increase with various rates over different frequency ranges. All the specimens demonstrate a change in the behaviour at frequencies above $20-50 \mathrm{~Hz}$, with increasing $\tan \delta$. It indicates that different energy dissipation mechanisms were activated at different frequency ranges. It was noticed that the frequency range from $0.1 \mathrm{~Hz}$ to $10 \mathrm{~Hz}$ for all the anatomical positions and both directions had a regimes with a steep negative slope. Generally, for both longitudinal and transverse directions, the loss factor has the minimum within the studied frequency range that is predominantly contained in normal activities. The data showed anisotropic and position-sensitive character of the loss factor for bovine femoral cortical bone tissue. Table 7 demonstrates the difference between the loss factor values for studied directions and anatomical positions for the physiological 
frequency range of $0.1 \mathrm{~Hz}-10 \mathrm{~Hz}$. In all the cases, the loss energy due to viscous effects was low, in the range of $0.035-0.1$, close to that of the glassy state of polymers (around $0.1)$ and higher than that of metals $\left(10^{-3}\right.$ or less (Roderic, 2001)). Anisotropic ratios for the loss factor showed that at a low frequency level, $0.1 \mathrm{~Hz}$, a viscous response of the cortical bone tissue is almost isotropic. At a higher frequency, $10 \mathrm{~Hz}$, the loss factor in the longitudinal direction is higher than that of transverse direction.

\section{Discussion}

Our experimental study demonstrated that mechanical properties and behaviours of the bovine femoral cortical bone tissue are anisotropic and position-sensitive. Still, both features are relatively moderate with a lower contrast compared, e.g. to many structural composites. Stress-strain behaviours demonstrated pronounced non-linearity. Our findings are consistent with the non-linear behaviour of cortical bone tissue at small strains found in (Bonfield, 1978). Based on elastic properties, it is obvious from their position-sensitivity that changes in the mechanical properties are linked to changes in composition and/or microstructure. The reason for different mechanical properties at different anatomical positions stems from the non-uniform loading experienced by bone caused by body weight and muscle forces; according to the Wolf's law (Wolff, 1986), bones adapt themselves to be stiffer and stronger in positions subjected to higher loads. Results for longitudinal specimens from the anterior part of the femur suggest that they were subjected to the highest longitudinal loading while lateral to the lowest. The character for the transversal specimens is different; the medial part is the stiffest and the posterior is the weakest. All the obtained data are within the range for cortical bone 
tissue's moduli, accepted in the literature, suggested as 6-24 GPa in (Reilly and Burstein, 1975; Burstein et al., 1976) depending on parameters such as mineralization, porosity, and the method employed. Also the obtained ultimate strength showed an agreement with the literature data; for instance Currey (1959) reported the level of $112 \mathrm{MPa}$ for the longitudinal direction of bovine femur, while Sweeney et al. (1956) $129 \mathrm{MPa}$. For the transversal directions, (Burstein et al., 1972) gives a value of $52 \pm 8 \mathrm{MPa}$. No specific information on the anatomical position of specimens was given in those works. It was also noticed that the hysteresis loops, indicating energy lost in loading-unloading cycles in tension tests, were noticeably larger for longitudinal specimens than for transverse ones. As the closed hysteresis loop supports the assumption of viscoelasticity of the cortical bone tissue, it was necessary to quantify its viscoelastic properties to be accounted later in numerical modelling of its deformation and fracture. The viscoelastic properties were investigated using different methods: strain-rate sensitivity, creep, relaxation and DMA. The strain-rate sensitivity results showed different behaviours at different strain rates. Based on those behaviours, it was found that strain rate-related changes in the levels of elastic modulus can be neglected at strain rates higher than $1 \mathrm{~s}^{-1}$. This assumption is consistent with elastic modulus values of $10.3-22.1 \mathrm{GPa}$, obtained at strain rates of $0.005-150 \mathrm{~s}^{-1}$ (Wood, 1971). The value of the elastic modulus at a strain rate of $150 \mathrm{~s}^{-1}$ is not too far from $21 \mathrm{GPa}$ obtained at strain rate $1 \mathrm{~s}^{-1}$. This allows development of fracture models for cortical bone caused by dynamic events that usually occur with high strain rates, up to $10^{5} \mathrm{~s}^{-1}$. There was no significant difference in the material constants describing the secondary creep behaviour, for longitudinal or transverse directions and for all the anatomical positions examined. In this study, a 
threshold stress level at around $17 \mathrm{MPa}$ was found, above which the secondary creep behaviour can be observed. It means that initiation of secondary creep requires levels of static load beyond the range that occurs during normal activities (Roderic, 2001). A study in (Parsamian and Norman, 2000) demonstrated that above 75.3 MPa the strain rate starts to increase dramatically and stiffness starts to decrease, characterising transition to tertiary creep.

The DMA technique provides magnitudes of the elastic modulus differing by a factor of two from results of the quasi-static tests, The differences were due to the use of various principles of testing and specimen's dimensions (Table 1). This conclusion is consistent with the results of another study that showed the specimen-size effect on the storage modulus (Yamashita, 2001). Though DMA underestimated the values of elastic moduli, the anisotropic ratios for two directions for all positions were practically in the same range as those obtained from the quasi-static results $-1.2-1.8$. Our DMA-based findings confirmed the relatively low-level anisotropic character and position-sensitivity of the bovine cortical bone tissue. Different trends for both storage moduli and loss factors were observed for different directions and positions with a frequency increase. In the normal activity frequency range, cortical bone behaved nearly fully elastically, with the loss factor reaching its minimum. The tendency of the loss factor to reach its minimum in the frequency range predominately contained in the normal activities is in agreement with previous works using different species and methods (Lakes et al., 1979a; Sasaki et al., 1993; Garner et al., 2000). Also, the obtained results (see Table 7) showing lower values of $\tan \delta$ around $10 \mathrm{~Hz}$ are in agreement with the data obtained in (Garner et al., 2000). Results of our study - as well as those in (Garner et al., 2000) - do not confirm the 
optimal shock-absorber role of bone based on its viscoelastic response suggested in (Paul et al., 1978). There are two most likely reasons that cause damping in the physiological frequency response: molecular mobility of a collagen phase, and presence of fluid inside the bone. Macro-scale bone viscoelasticity is due to dissipation energy linked to several mechanisms. Since bone has a hierarchical structure, viscolelasticity can arise from various processes at different scales. For instance, at the molecular level, the collagen phase can incur significant viscoelasticity (Sasaki et al., 1993). At the microstructural level, many interfaces such as cement lines and the boundaries between the lamellae within osteons dissipate some energy (Katz, 1980). A viscous motion of the cement line also contributes to viscoelasticity, in particular in cases of long-time loading (Lakes and Saha, 1979). Another mechanism that can cause damping is thermoelastic coupling (Garner et al., 2000). Thermoelastic damping arising from a heat flow between osteons inside bone may account for some of energy loss in the frequency range of $0.01 \mathrm{~Hz}-10$ Hz (Lakes and Katz, 1979b; 1979c). Fluid flow in porous media can also contribute to viscoelasticity in hard tissues like bone (Lakes and Katz, 1979b; 1979c).

\section{Conclusions}

One of the most important requirements for adequate modelling of fracture of, and deformation in, cortical bone tissue is comprehensive characterisation of its mechanical properties. This was the motivation behind our study to experimentally measure its main mechanical properties. The obtained experimental data cover a wide range of loading conditions and respective deformation mechanisms to provide a basis for future numerical simulations. The undertaken experimental studies include the characterisation of elastic-plastic behaviour as well as viscoelastic properties using different methods. All 
the data apart from those on strain-rate sensitivity were measured for two main directions and for various anatomical positions to quantify the anisotropy and position-sensitivity for further introduction into the numerical models. The main conclusions based on the experimental results are:

- The elastic moduli obtained from the unloading part of the cyclic tension test are more accurate than those from the initial portion or based on the DMA storage moduli, the first and second cycles elastic moduli were close to each other while differing from the initial ones.

- The specimens from the anterior anatomical position showed the highest values of elastic moduli in the longitudinal direction and the lateral ones demonstrated the lowest; for the transversal direction, the medial anatomical position specimens had the highest moduli, while the posterior ones the lowest. Those extremes could be used as to bounds in finite-element numerical simulations of local deformation and fracture processes; the entire data is necessary for a numerical study of the global bone's response.

- The energy loss, measured as the area of the hysteresis loop in cyclic tension tests, was higher for the longitudinal direction, this fact can be used as one of the verification criteria of a finite-element model.

- The changes in the elastic moduli can be neglected at higher strain rates beyond 1 $\mathrm{s}^{-1}$. This phenomenon allows implementing different experimental-based stressstrain behaviours into bone fracture models to account for strain-rate sensitivity. 
- The increase in the storage moduli with the increase of the frequency is consistent with the strain-rate sensitivity results: as the strain rate increases the elastic modulus increases; this data can also be used as a verification criterion for a finite-element model.

- Tan $\delta$ has a minimum for all anatomical positions and both directions over the frequency range of $0.1 \mathrm{~Hz}-100 \mathrm{~Hz}$ corresponding to normal activities.

\section{References}

Abaqus, Dassault Systèmes Simulia Corp., Providence, RI, USA, 2009. Theory manual Version 6.9-1 Edition,.

Augat, P., Schorlemmer, S., 2006.The role of cortical bone and its microstructure in bone strength. Age and Ageing. 35 (S2), ii27-ii31.

Bonfield, W., O'connor, P., 1987. Anelastic deformation and the friction stress of bone. J. Mat. Sci. 13, 202-207.

Bonfield, W., Tully, A.E., 1982. Ultrasonic analysis of the Young's modulus of cortical bone. J Biomed Eng. 4, 23-27.

Burstein, A.H., Currey, J.D., Frankel, Y.H., Reilly, D.T., 1972. The ultimate properties of bone tissue: The Effects of Yielding. J Biomech. 5, 34-44.

Burstein, A.H., Reilly, D.T., Martens, M., 1976. Aging of bone tissue: mechanical properties. J Bone Joint Surg. 58-A, 82-86.

Cotton, J.R., Winwood, K., Zioupos, P., Taylor, M., 2005. Damage Rate is a predictor of fatigue life and creep strain rate in tensile fatigue of human cortical bone samples. J Biomech Eng.-T ASME. 127(2), 213-219. 
Currey, J.D., 1959. Differences in the tensile strength of bone of different histological types. J Anat. 93, 87-95.

Currey, J.D.,1965. Anelasticity in bone and echinoderm skeletons. J Exp Biol. 43, 279292.

Currey, J.D., 2004. Tensile yield in compact bone is determined by strain, post yield behaviour by mineral content. J Biomech. 37, 549-556.

Ferreira, F., Vaz, M.A., Simões, J.A., 2005. Mechanical properties of bovine cortical bone at high-strain rate. Mater Charact. 57, 71-79.

Fondrk, M., Bahniuk, E., Davy, D.T., Michales, C., 1988. Some viscoelastic characteristics of bovine bone and human bone. J Biomech. 21(8), 623-630.

Garner, E., Lakes, R., Lee, T., Swan, C., Brand, R., 2000. Viscoelastic dissipation in compact bone: Implications for stress-induced fluid flow in bone. J biomed eng, Transactions of the ASME. 122, 166-172.

Johnson, T.P.M., Socrate, S., Boyce, M.C. 2010. A viscoelastic, viscoplastic model of cortical bone valid at low and high strain rates. Acta Biomater, doi:10.1016/j.actbio.2010.04.017.

Katz, J.L., 1980. Anisotropy of young's modulus of bone. Nature. 283, 106-107.

Lakes, R.S., Katz, J.L. Sternstein, S.S., 1979a . Viseoelastic properties of wet cortical bone-1, Torsional and biaxial studies. J Biomech. 12, 657-678.

Lakes, R.S., Saha, S., 1979. Cement line motion in bone. Science. 204, 501-503.

Lakes, R.S., Katz, J.L., 1979b .Viscoelastic properties of wet cortical bone: Part II, relaxation mechanisms. J Biomech. 12, 679-687.

Lakes, R.S., Katz, J.L., 1979c. Viscoelastic properties of wet cortical bone: Part III, A non-linear constitutive equation. J Biomech. 12, 689-698.

Lasaygues , P., Pithioux, M., 2002. Ultrasonic characterization of orthotropic elastic bovine bones. Ultrasonics. 39, 567-573.

Mano, J.o.F., 2005. Viscoelastic properties of bone: Mechanical spectroscopy studies on a chicken model. Mater Sci Eng. C25, 145-152. 
Parsamian, G., Norman, T., 2000. A viscoelastic damage model for human cortical bone. 48th Annual Meeting of the Orthopaedic Research Society, Poster No:0546, West Virginia University, Morgantown

Paul, I.L., Munro, M.B., Abernethy, P.J., Simon, S.R., Radin, E.L., Rose, R.M., 1978. MusculoSkeletal shock absorption: Relative contribution of bone and soft tissues at various frequencies. J Biomech. 11, 237-239.

Pithioux, M., Lasaygues, P., Chabrand, P., 2002. An alternative ultrasonic method for measuring the elastic properties of cortical bone. J Biomech. 35, 961-968.

Raftopoulos, D., Katsamanis., E., Saul, F., Liu, W., Saddemi, S., 1993. An intermediate loading rate technique for the determination of mechanical properties of human femoral cortical bone. J Biomed Eng. 15, 60-66.

Reilly, D.T., Burstein, A.H., 1975. The elastic and ultimate properties of compact bone tissue. J Biomech. 8, 393-405.

Rho, J.Y., 1996. An ultrasonic method for measuring the elastic properties of human tibial cortical and cancellous bone. Ultrasonics. 34, 777-783.

Rho, J.Y., Kuhn-Spearing, L., Zioupos, P.,1998. Mechanical properties and the hierarchical structure of bone. Medical Engineering \& Physics 20 (2): 92-102.

Smith, J.W. Walmsley, R., 1957. Elastic after-effect, plasticity and fatigue in bone. J Anat. 91, 603-604.

Lakes, R. 2001. Viscoelastic Properties of Cortical Bone, in: Cowin, S.C.,(ed), Bone Mechanics Handbook. CRC Press, Boca Raton, Florida, pp. 11-1:11-5.

Sasaki, N., Nakayama, Y., Yoshikawa, M., Enyo, A., 1993. Stress relaxation function of bone and bone collagen. J Biomech. 26, 1369-1376.

Sasaki N., Atsushi, E., 1995. Viscoelastic properties of bone as a function of water content. J Biomech. 28, 809-815.

Sedlin, E.D., 1965. A rheological model for cortical bone Acta Orthop Scand, Suppl. 83, 77.

Sweeney, W., Kroon, R.P., Byersr, K., 1965. Mechanical characteristics of bone and its constituents. ASME 65-WA/HUF-7. 
Uteri'kin, A.A., Sveshnikova, A.A., 1973. Effect of duration of Loading on the deformation properties of compact bone material Arkhiv Anatomii, Gistologii, i I mbriologii. 64(4), 14-20.

Vilks, Y.V., Kent-s., I.V., 1975. Creep of compact human bony tissue under tension. Institute of Polymer Mechanics, Academy of Sciences of the Latvian SSR, Riga. Translated from Mekhanika Polimerov. 4, 634-638.

Wachter, N.J., Krischak, G.D., Mentzel, M., Sarkar, M.R., Ebinger, T., Kinzl, L., Claes, L., Augat, P., 2002. Correlation of bone mineral density with strength and microstructural parameters of cortical bone in vitro. bone. 31, 90-95.

Wang, T., Freng, Z., 2005. Dynamic mechanical properties of cortical bone: the effect of mineral content. Mater lett. 59, 2277-2280.

Wolff J., 1986. The Law of Bone Remodeling, Berlin Heidelberg New York: Springer, (translation of the German 1892 edition).

Wood, J.L., 1971. Dynamic response of human cranial bone. J Biomech. 4(1), 1-12.

Wrightt, T.M., Hayes, W.C., 1976. Tensile testing of bone over a wide range of strain rates: effects of strain rate, microstructure and density. Med Biol Eng, 671-680.

Yamashita, J., Furman, B.R., Rawls, H.R., Wang, X.D., Agrawal, C.M., 2001. The use of Dynamic Mechanical Analysis to assess the viscoelastic properties of human cortical bone. J Biomed Res Appl Biomater. 58 (1), 47-53.

Yeni, Y.N., Christopherson, G.T., Turner, A.S., Les, C.M., Fyhrie, D.P., 2004. Apparent viscoelastic anisotropy as measured from non-destructive oscillatory tests can reflect the presence of a flaw in cortical bone. J Biomed Mater Res. 69A, 124-130.

Yoon, H.S., Katz, J.L., 1976. Ultrasonic wave propagation in human cortical bone - I. Theoretical considerations for hexagonal symmetry. J Biomech. 9, 407-412.

Zioupos, P., Currey, J.D., 1998. Changes in the stiffness, strength, and toughness of human cortical bone with age. Bone. 22, 57-66.

Zioupos, P., Currey, J.D., Hamer, A.J., 1999. The role of collagen in the declining mechanical properties of aging human cortical bone. J Biomed Mater Res. 45, 108-116. 


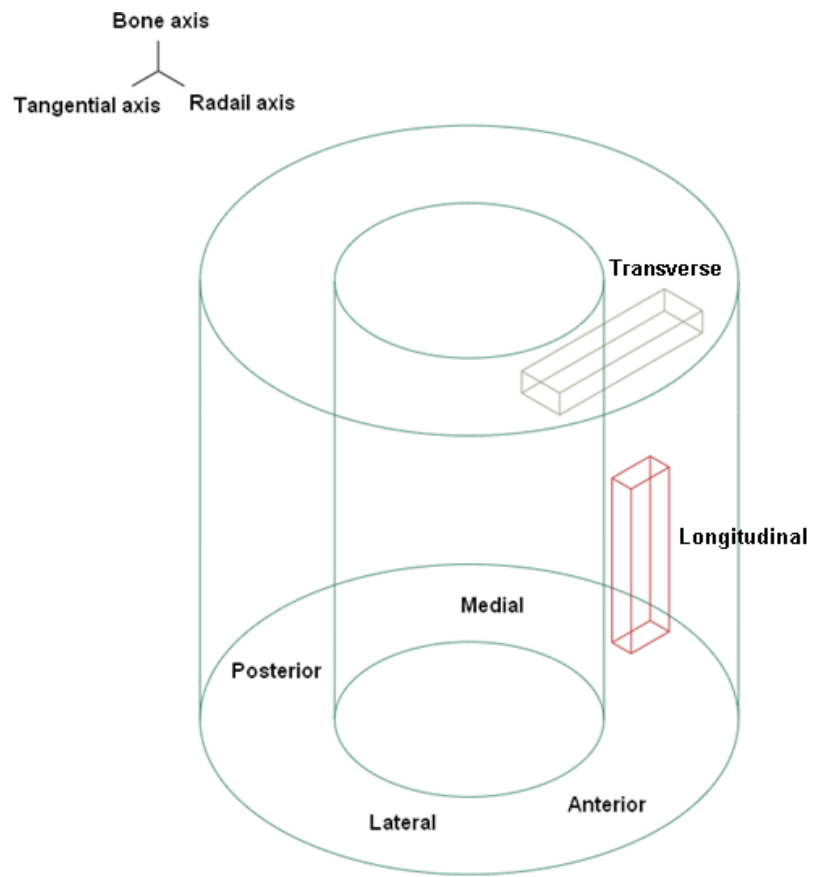



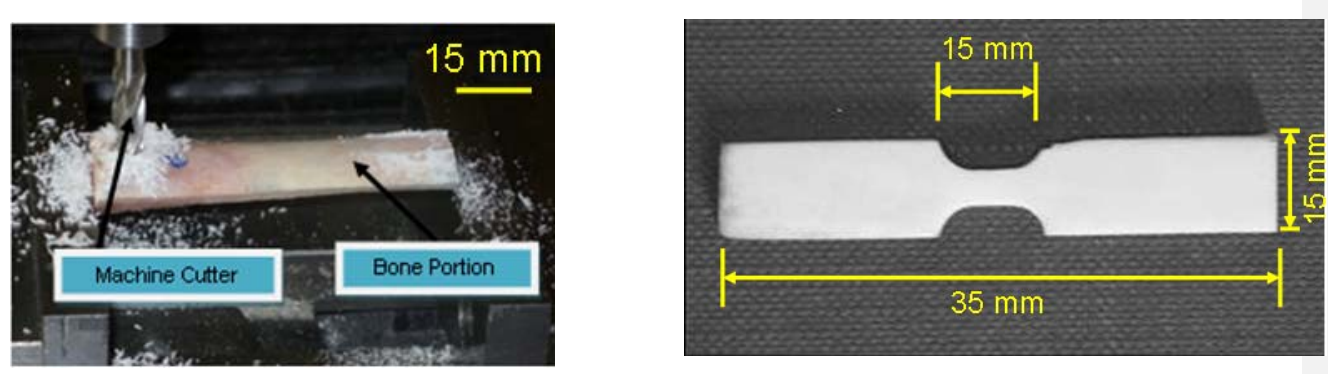

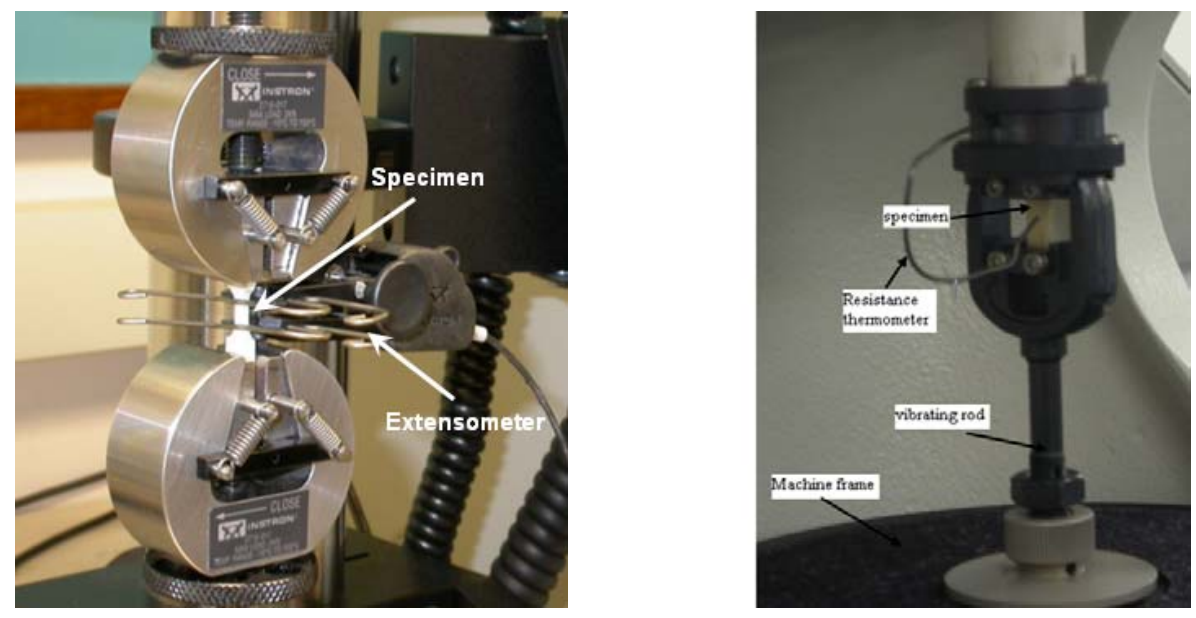


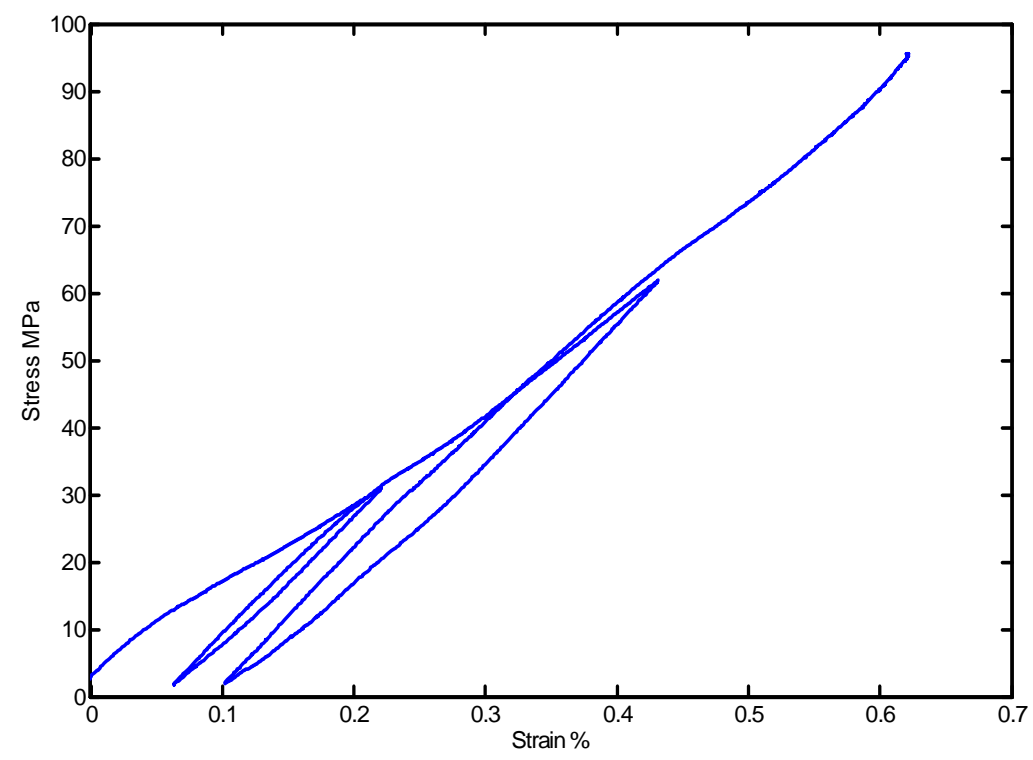


(a)

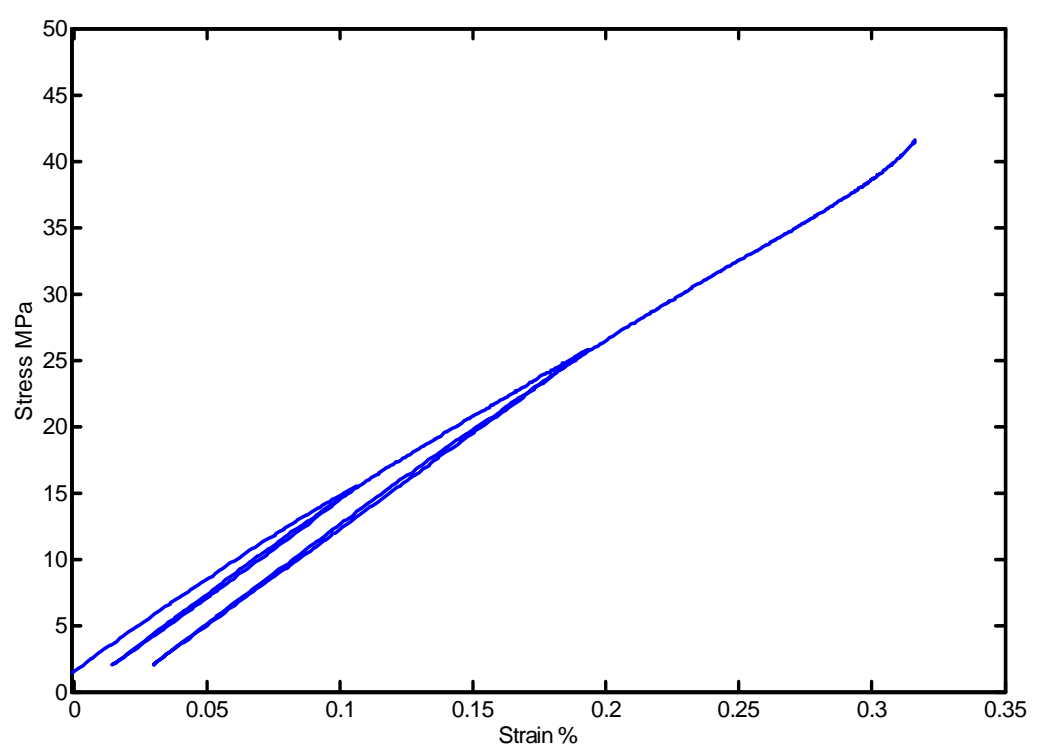

(b) 


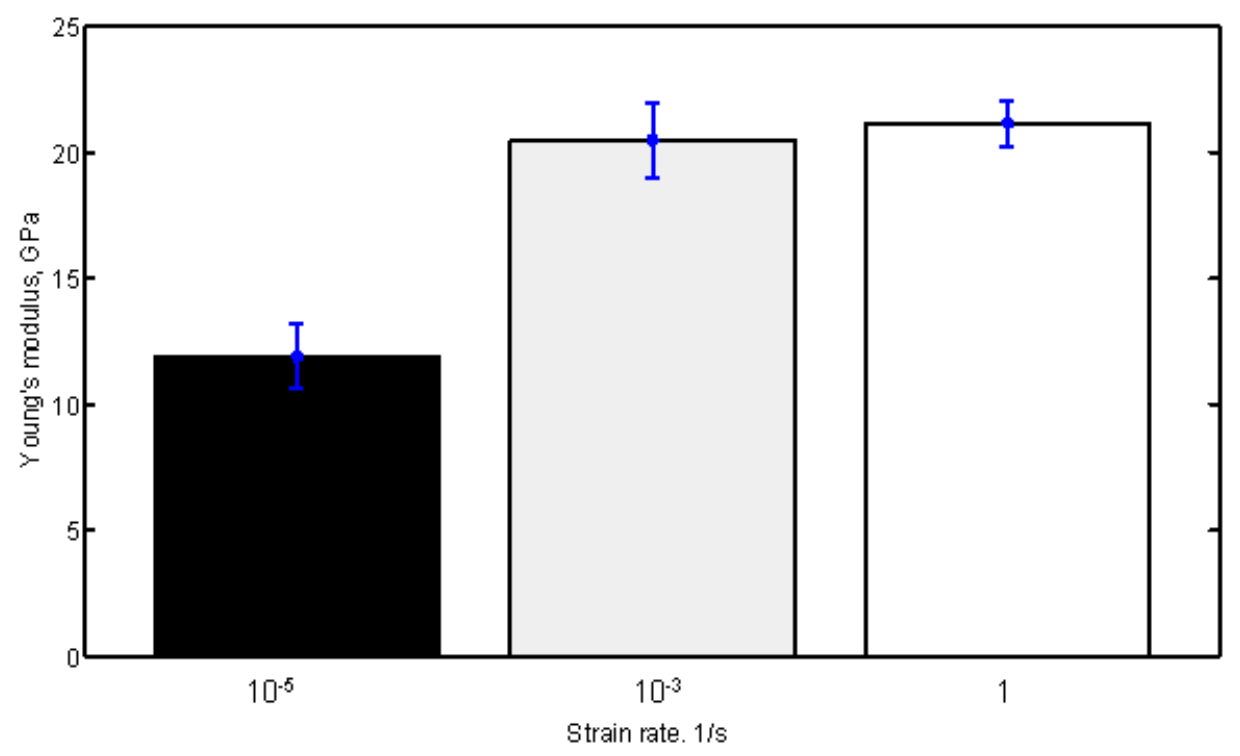

Comment [VS8]: Make bars at least 


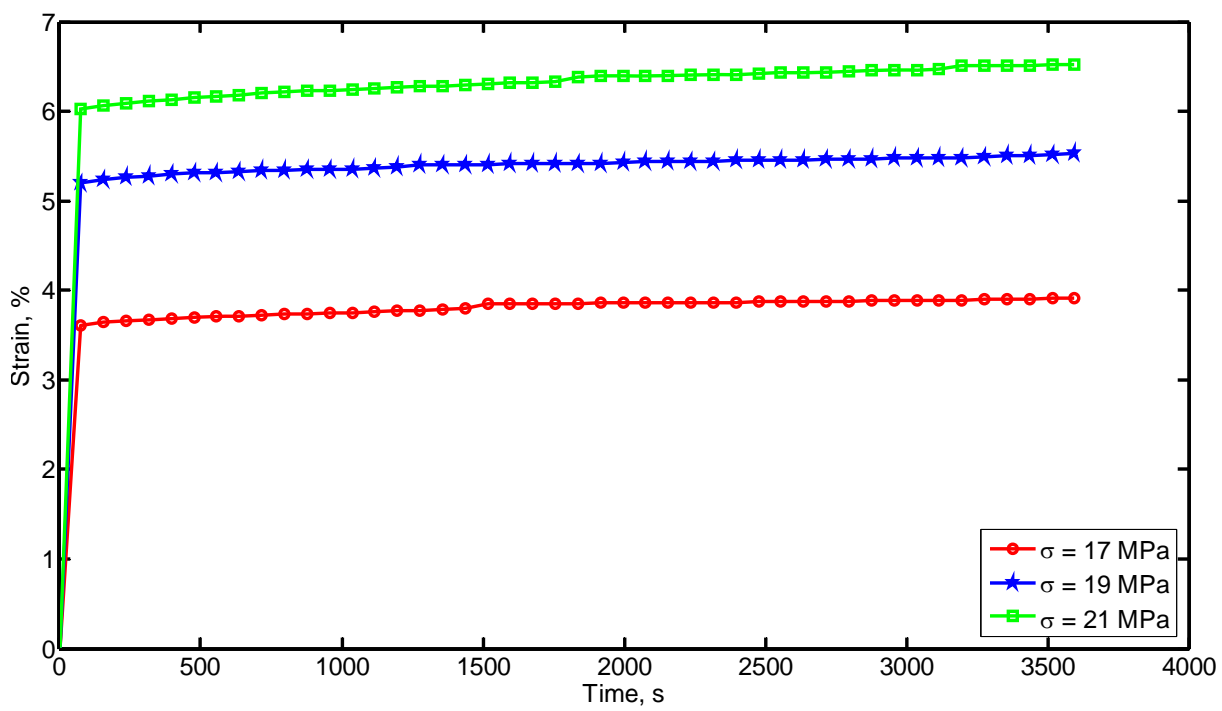

(a)

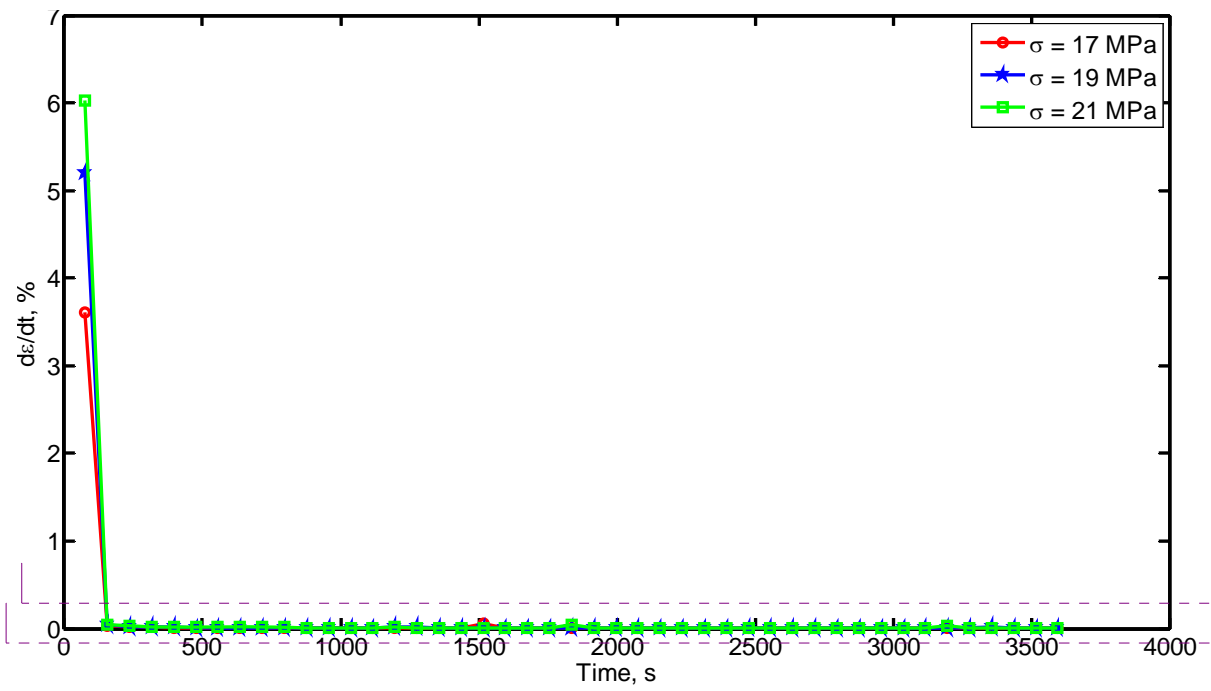

Comment [VS9]:

Comment [VS10]: Units for axis of ordinates whould be $1 / \mathrm{s}$

(b) 







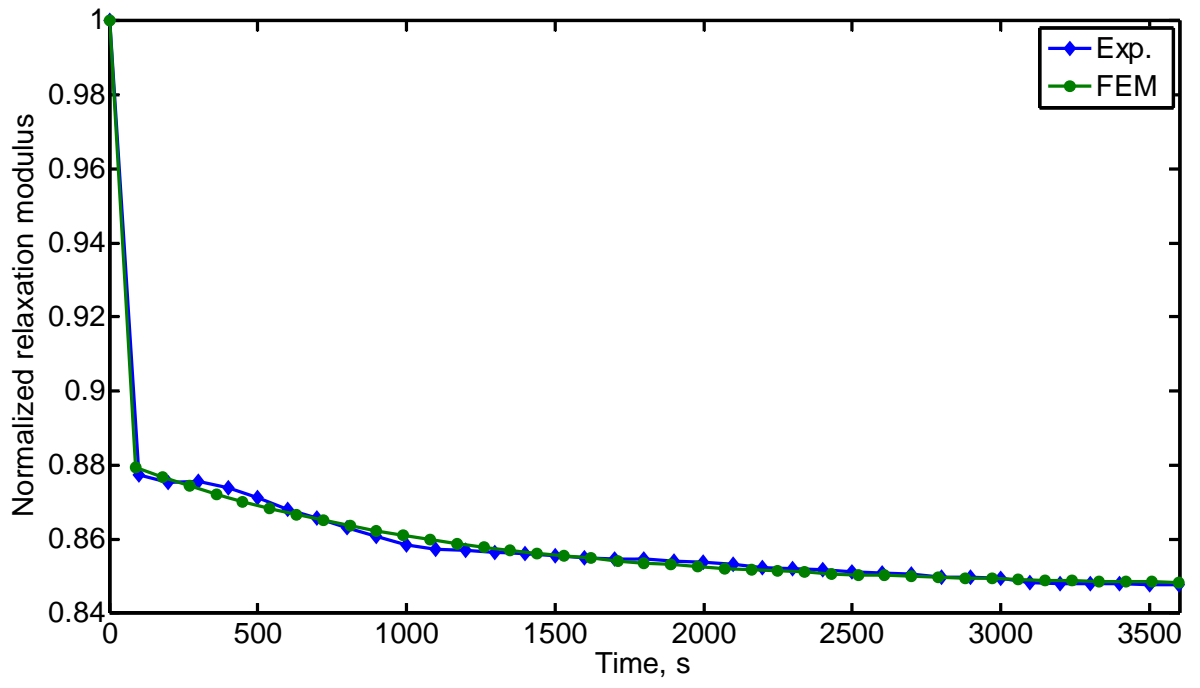




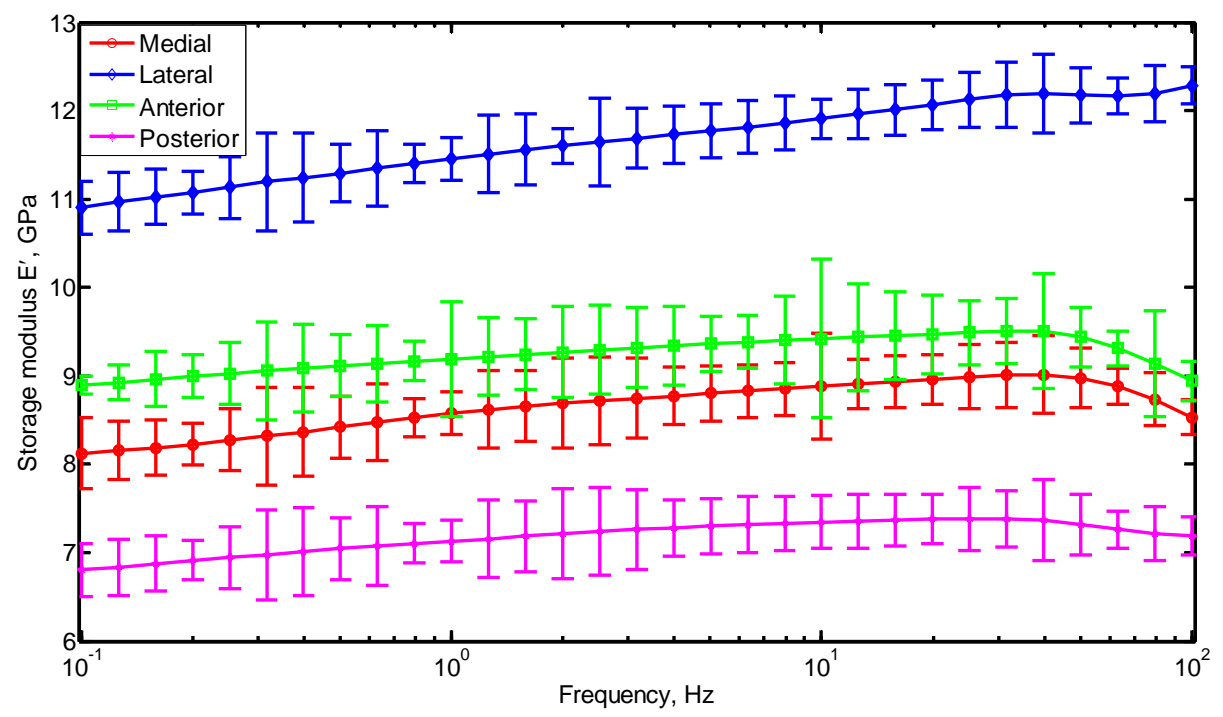




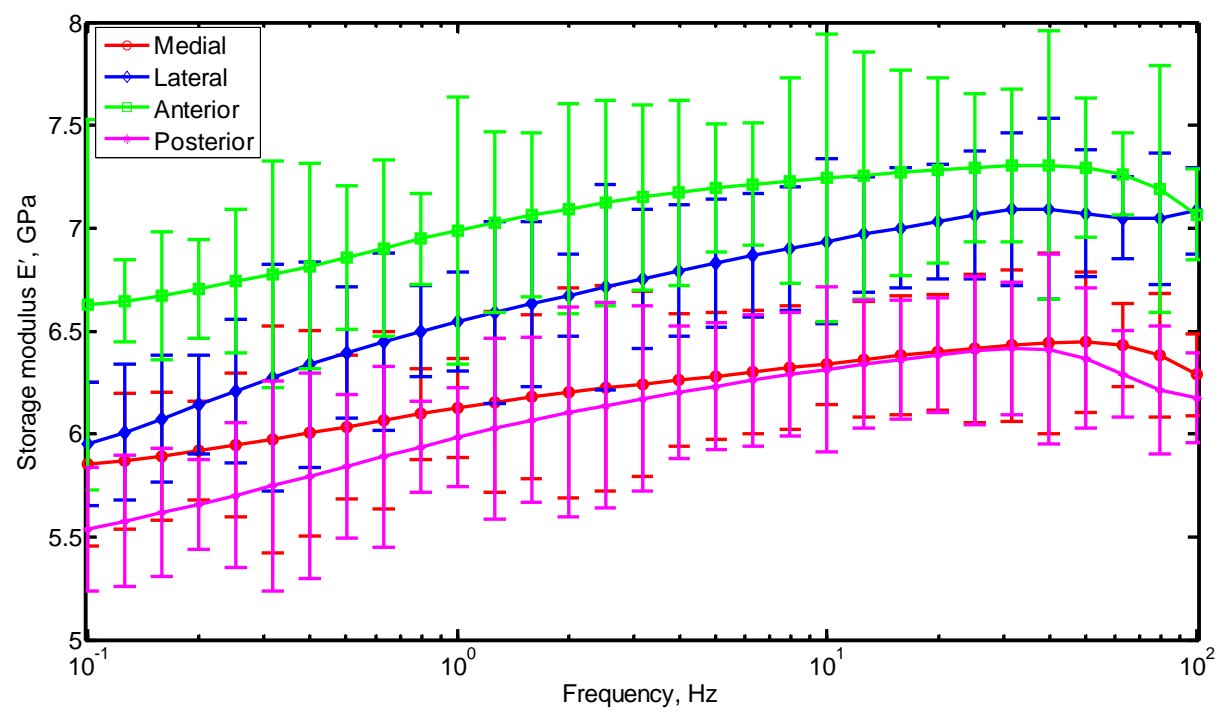

Comment [VS11]: Use thicker line for averages but NOT for error bars 


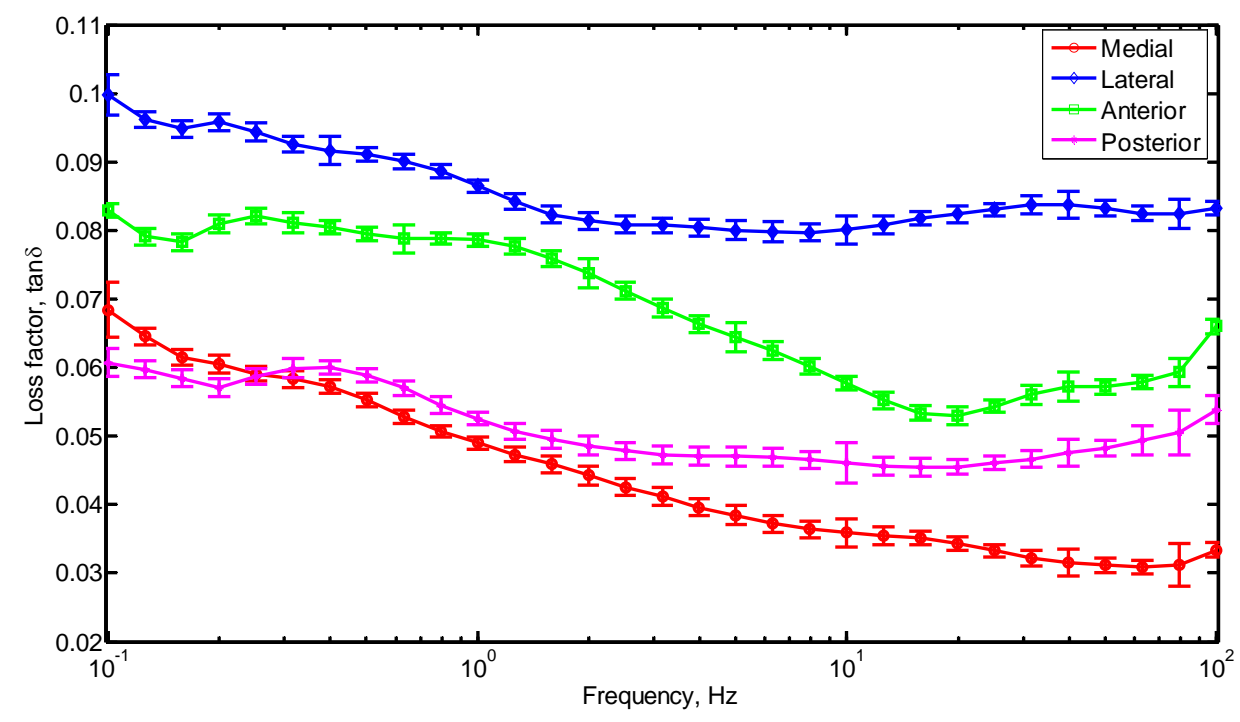

(a)

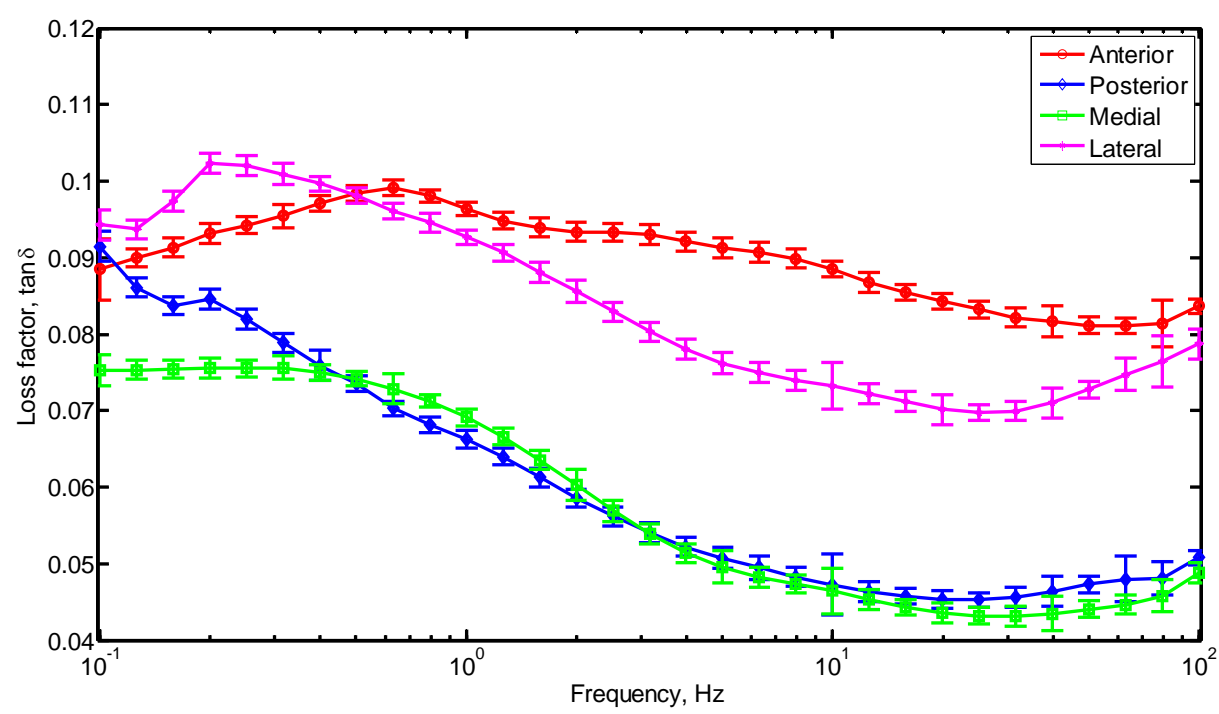


(b)

\section{Figure captions}

Fig. 1 Cortical bone axes and anatomical positions (Ant - anterior, Post - posterior, Med medial, Lat - lateral)

Fig. 2 Excising bovine cortical bone using milling machine (a) and specimen of Group A (b)

Fig. 3 Specimens in Instron MicroTester 5848 (a) and DMA (tension mode) (b)

Fig. 4 Stress-strain curves of loading-unloading cycles for longitudinal (a) and transverse (b) specimens of bovine femoral cortical bone tissue

Fig. 5 Elastic moduli of cortical bone tissues at various strain rates, error bars represent standard deviation

Fig. 6 Typical creep response for anterior longitudinal bovine femoral cortical bone tissue for various stress levels (a), and respective strain rates (b)

Fig. 7 Typical stress-time profiles for anterior longitudinal bovine femoral cortical bone tissues in relaxation tests for various initial displacements

Fig. 8 Dimensionless relaxation modulus for medial longitudinal bone: experimental and finite-element data

Fig. 9 Mean storage modulus $E^{\prime}$ of bovine femoral cortical bone tissues for longitudinal direction in different anatomical positions, error bars represent standard deviation

Fig. 10 Mean storage modulus $E^{\prime}$ of bovine femoral cortical bone tissues for transverse direction in different anatomical positions, error bars represent standard deviation

Fig. 11 Mean loss factor tan $\delta$ for different anatomical positions of bovine femoral cortical bone tissue for longitudinal (a) and transverse (b) specimens, error bars represent standard deviation 
Table 1 Dimensions of bovine cortical bone specimen. The gage length for all the specimens was $10 \mathrm{~mm}$ and the dimensions were the same for all four anatomical

\begin{tabular}{|ccccc|}
\hline Group & $\begin{array}{c}\text { Axis } \\
\text { direction }\end{array}$ & $\begin{array}{c}\text { Total length } \\
\mathbf{( m m})\end{array}$ & $\begin{array}{c}\text { Width } \\
\mathbf{( m m})\end{array}$ & $\begin{array}{c}\text { Thickness } \\
\mathbf{( m m})\end{array}$ \\
\hline \multirow{2}{*}{ A } & Bone axis & $35( \pm 0.11)$ & $4.5( \pm 0.09)$ & $2( \pm 0.01)$ \\
& Transverse & $25( \pm 0.19)$ & $4.5( \pm 0.08)$ & $2( \pm 0.011)$ \\
\hline B & Bone axis & $40( \pm 0.14)$ & $8( \pm 0.09)$ & $3( \pm 0.01)$ \\
\hline \multirow{2}{*}{ C } & Bone axis & $25( \pm 0.15)$ & $5( \pm 0.09)$ & $3( \pm 0.012)$ \\
& Transverse & $25( \pm 0.13)$ & $5( \pm 0.07)$ & $3( \pm 0.012)$ \\
\hline \multirow{2}{*}{ D } & Bone axis & $15( \pm 0.19)$ & $5( \pm 0.06)$ & $2.5( \pm 0.013)$ \\
& Transverse & $15( \pm 0.17)$ & $5( \pm 0.07)$ & $2.5( \pm 0.014)$ \\
\hline
\end{tabular}

positions in each group.

Table 2 Loading parameters in cyclic uniaxial tension tests

\begin{tabular}{|cccc|}
\hline $\begin{array}{c}\text { Axis direction } \\
\text { of specimen }\end{array}$ & Unloading force limits, $\mathbf{N}$ & Cycle 1 & Cycle 2 \\
\hline \multirow{2}{*}{ Longitudinal } & Upper limit & 400 & 800 \\
& Lower limit & 20 & 20 \\
\hline \multirow{2}{*}{ Transverse } & Upper limit & 150 & 250 \\
& Lower limit & 20 & 20 \\
\hline
\end{tabular}


Table 3 Elastic moduli and ultimate strength of bovine femoral cortical bone for various directions and anatomical positions.

\begin{tabular}{|c|c|c|c|c|c|c|}
\hline Direction & $\begin{array}{l}\text { Specimen } \\
\text { location }\end{array}$ & $\begin{array}{c}\text { Specimen } \\
\#\end{array}$ & $\begin{array}{c}\text { Initial } \\
\text { modulus } \\
\text { (GPa) }\end{array}$ & $\begin{array}{c}\text { First } \\
\text { unloading } \\
\text { cycle modulus } \\
(\mathrm{GPa}) \\
\end{array}$ & $\begin{array}{c}\text { Second } \\
\text { unloading } \\
\text { cycle modulus } \\
(\mathrm{GPa}) \\
\end{array}$ & $\begin{array}{c}\text { Ultimate } \\
\text { strength } \\
\text { (MPa) }\end{array}$ \\
\hline \multirow{16}{*}{ 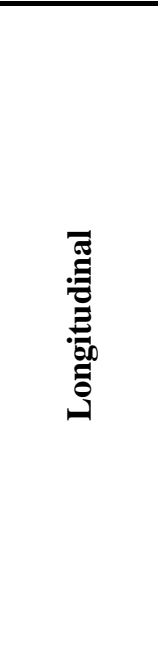 } & \multirow{4}{*}{ Anterior } & 1 & 23.77 & 24.18 & 24.18 & 124.30 \\
\hline & & 2 & 22.36 & 22.69 & 22.99 & 139.93 \\
\hline & & 3 & 23.31 & 24.33 & 24.57 & 88.51 \\
\hline & & Mean (SD) & $23.15( \pm 0.72)$ & $23.73( \pm 0.91)$ & $23.91( \pm 0.82)$ & $117.58( \pm 26.36)$ \\
\hline & \multirow{4}{*}{ Posterior } & 1 & 17.68 & 17.82 & 18.67 & 82.86 \\
\hline & & 2 & 19.69 & 20.16 & 19.69 & 97.52 \\
\hline & & 3 & 20.49 & 20.87 & 20.70 & 98.13 \\
\hline & & Mean (SD) & $19.29( \pm 1.45)$ & $19.62( \pm 1.60)$ & $19.69( \pm 1.02)$ & $92.84( \pm 8.65)$ \\
\hline & \multirow{4}{*}{ Medial } & 1 & 17.92 & 19.95 & 20.94 & 97.41 \\
\hline & & 2 & 21.74 & 22.27 & 22.94 & 106.66 \\
\hline & & 3 & 23.74 & 25 & 25.31 & 97.14 \\
\hline & & Mean (SD) & $21.13( \pm 2.96)$ & $22.41( \pm 2.53)$ & $23.06( \pm 2.19)$ & $100.40( \pm 5.42)$ \\
\hline & \multirow{4}{*}{ Lateral } & 1 & 13.65 & 14.58 & 14.95 & 63.48 \\
\hline & & 2 & 16.67 & 17.21 & 16.95 & 80.53 \\
\hline & & 3 & 15.11 & 16.44 & 16.93 & 52.55 \\
\hline & & Mean (SD) & $15.14( \pm 1.51)$ & $16.08( \pm 1.35)$ & $16.28( \pm 1.15)$ & $65.52( \pm 14.10)$ \\
\hline \multirow{16}{*}{ 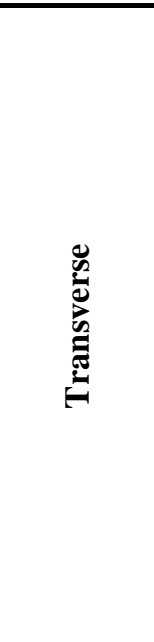 } & \multirow{4}{*}{ Anterior } & $\overline{1}$ & 14.15 & 14.49 & 14.35 & 26.47 \\
\hline & & 2 & 12.69 & 13.16 & 13.52 & 24.87 \\
\hline & & 3 & 12.76 & 13.59 & 13.92 & 25.12 \\
\hline & & Mean (SD) & $13.20( \pm 0.82)$ & $13.75( \pm 0.68)$ & $13.93( \pm 0.42)$ & $25.49( \pm 0.86)$ \\
\hline & \multirow{5}{*}{ Posterior } & 1 & 9.35 & 9.74 & 9.52 & 26.60 \\
\hline & & 2 & 9.33 & 9.80 & 9.58 & 24.86 \\
\hline & & 3 & 11.07 & 11.28 & 11.15 & 29.42 \\
\hline & & Mean (SD) & $9.92( \pm 0.10)$ & $10.27( \pm 0.87)$ & $10.08( \pm 0.92)$ & $26.96( \pm 2.30)$ \\
\hline & & 1 & 14.64 & 14.65 & 14.66 & 33.75 \\
\hline & \multirow{3}{*}{ Medial } & 2 & 14.52 & 15 & 14.75 & 42.23 \\
\hline & & 3 & 14.85 & 15.15 & 15.20 & 41.12 \\
\hline & & Mean (SD) & $14.67( \pm 0.17)$ & $14.93( \pm 0.26)$ & $14.87( \pm 0.29)$ & $39.03( \pm 4.61)$ \\
\hline & \multirow{4}{*}{ Lateral } & 1 & 11.95 & 13.01 & 12.32 & 30.19 \\
\hline & & 2 & 12.15 & 12.41 & 12.28 & 30.70 \\
\hline & & 3 & 9.43 & 9.85 & 10.31 & 19.39 \\
\hline & & Mean (SD) & $11.18( \pm 1.52)$ & $11.76( \pm 1.68)$ & $11.64( \pm 1.15)$ & $26.76( \pm 6.39)$ \\
\hline
\end{tabular}


Table 4 Anisotropic ratios for elastic moduli of bovine femoral cortical bone tissue for different anatomical positions

\begin{tabular}{|cccc|}
\hline $\begin{array}{c}\text { Anatomical } \\
\text { position }\end{array}$ & Initial & $\begin{array}{c}\text { Anisotropy Ratio } \\
\text { First unloading } \\
\text { cycle }\end{array}$ & $\begin{array}{c}\text { Second unloading } \\
\text { cycle }\end{array}$ \\
\hline Anterior & 1.75 & 1.73 & 1.67 \\
\hline Posterior & 1.94 & 1.91 & 1.95 \\
\hline Medial & 1.44 & 1.50 & 1.49 \\
\hline Lateral & 1.35 & 1.37 & 1.38 \\
\hline
\end{tabular}

Table 5 Material constants for first and second terms of Prony series for medial longitudinal cortical bone specimens

\begin{tabular}{|ccc|}
\hline$i$ & $e_{i}$ & $\tau_{i}$ \\
\hline 1 & 0.11768 & 7.6998 \\
& & \\
\hline & & 1061.7 \\
\hline
\end{tabular}


Table 6 Storage modulus, E' of bovine femoral cortical bone tissue in longitudinal and transverse directions for various anatomical positions.

\begin{tabular}{|c|c|c|c|c|c|}
\hline \multirow{2}{*}{$\begin{array}{c}\text { Anatomical } \\
\text { position }\end{array}$} & \multirow{2}{*}{ Direction } & \multicolumn{2}{|c|}{ Storage Modulus (GPa) } & \multicolumn{2}{|c|}{ Anisotropy ratio } \\
\hline & & $0.1 \mathrm{~Hz}$ & $10 \mathrm{~Hz}$ & $0.1 \mathrm{~Hz}$ & $10 \mathrm{~Hz}$ \\
\hline Anterior & $\begin{array}{c}\text { Longitudinal } \\
\text { Transverse }\end{array}$ & $\begin{array}{r}8.89( \pm 0.4) \\
6.63( \pm 0.4)\end{array}$ & $\begin{array}{l}8.94( \pm 0.6) \\
7.25( \pm 0.2)\end{array}$ & 1.34 & 1.23 \\
\hline Posterior & $\begin{array}{c}\text { Longitudinal } \\
\text { Transverse }\end{array}$ & $\begin{array}{l}6.81( \pm 0.3) \\
5.54( \pm 0.1)\end{array}$ & $\begin{array}{l}7.34( \pm 0.6) \\
6.31( \pm 0.4)\end{array}$ & 1.23 & 1.16 \\
\hline Medial & $\begin{array}{c}\text { Longitudinal } \\
\text { Transverse }\end{array}$ & $\begin{array}{l}8.12( \pm 0.1) \\
5.85( \pm 1.9)\end{array}$ & $\begin{array}{l}8.88( \pm 0.9) \\
6.34( \pm 0.7)\end{array}$ & 1.39 & 1.40 \\
\hline Lateral & $\begin{array}{c}\text { Longitudinal } \\
\text { Transverse }\end{array}$ & $\begin{array}{l}10.9( \pm 0.3) \\
5.95( \pm 0.3)\end{array}$ & $\begin{array}{c}11.91( \pm 0.3) \\
6.94( \pm 0.4)\end{array}$ & 1.83 & 1.72 \\
\hline
\end{tabular}


Table 7 Loss factor, $\tan \delta$ of bovine femoral cortical bone tissue in longitudinal and transverse directions for various positions

\begin{tabular}{|c|c|c|c|c|c|}
\hline \multirow{2}{*}{$\begin{array}{c}\text { Anatomical } \\
\text { position }\end{array}$} & \multirow{2}{*}{$\begin{array}{c}\text { Axis } \\
\text { direction }\end{array}$} & \multicolumn{2}{|c|}{ Loss factor } & \multicolumn{2}{|c|}{ Anisotropy ratio } \\
\hline & & $0.1 \mathrm{~Hz}$ & $10 \mathrm{~Hz}$ & $0.1 \mathrm{~Hz}$ & $10 \mathrm{~Hz}$ \\
\hline \multirow{2}{*}{ Anterior } & Longitudinal & $0.083( \pm 0.004)$ & $0.058( \pm 0.002)$ & \multirow{2}{*}{1.14} & \multirow{2}{*}{1.06} \\
\hline & Transverse & $0.095( \pm 0.004)$ & $0.061( \pm 0.001)$ & & \\
\hline \multirow{2}{*}{ Posterior } & Longitudinal & $0.061( \pm 0.003)$ & $0.046( \pm 0.002)$ & \multirow{2}{*}{1.07} & \multirow{2}{*}{0.88} \\
\hline & Transverse & $0.065( \pm 0.002)$ & $0.040( \pm 0.004)$ & & \\
\hline \multirow{2}{*}{ Medial } & Longitudinal & $0.068( \pm 0.001)$ & $0.035( \pm 0.001)$ & \multirow{2}{*}{1.08} & \multirow{2}{*}{1.02} \\
\hline & Transverse & $0.074( \pm 0.003)$ & $0.036( \pm 0.002)$ & & \\
\hline \multirow{2}{*}{ Lateral } & Longitudinal & $0.099( \pm 0.002)$ & $0.080( \pm 0.003)$ & \multirow{2}{*}{0.99} & \multirow{2}{*}{0.60} \\
\hline & Transverse & $0.098( \pm 0.003)$ & $0.048( \pm 0.002)$ & & \\
\hline
\end{tabular}

